\title{
Metaphysics and medical ethics: a reply
}

\author{
Grant Gillett University of Otago Medical School, New Zealand
}

\section{Author's abstract}

The total longitudinal form view of human beings is a metaphysical view which aims to locate our moral judgements about human embryos in a broader set of attitudes and characterisations. On this basis it has explanatory power and a real function in that it grounds our ethical discussion of embryos in other discourses. Contra Leavitt (1), this grounding suggests a broader criterion of relevance for metaphysical discussion than asking 'what comes out of' such a discussion for a particular ethical dilemma.

Leavitt (1) argues against our attempts (2) to justify a corpus of moral intuitions about embryos because he cannot see 'what comes out of it'. We attempted to explain a range of moral attitudes to embryos on the basis of a particular metaphysical view and we claimed that that view was superior to others in yielding an understanding of our moral phenomenology in this area. Leavitt's contention is that philosophical metaphysics can often be 'like idle wheels which make no difference to our moral decisions' (3) and that the Total Longitudinal Form (TLF) view of embryos is idle in this way. I will contend that our view is not an 'idle wheel' and that there are several reasons to reject both his scepticism about metaphysics and his demand for 'the bottom line' test of ethical relevance, namely:

1) Moral values are not independent of other considerations but are based on facts about the nature of the things they involve.

2) Particularities of a given case affect our moral judgements about that case but do so against a background of connexions between metaphysical and ethical features of cases of that general type.

3) To explain our moral judgements is, in part, to understand them in ways that allow us to explore, review, formulate, and possibly revise our thought in areas where it is tentative, insecure or produces conflicts. In addition I will argue that:

\section{Key words}

Embryos; metaphysics; ethics; form.
4) The longitudinal view of human beings explainsi why in general we have certain moral attitudes tothings of a type which, viewed in other ways, do notir seem to ground those attitudes.

It remains to make these claims good and show how $\vec{z}$ even if in a particular case nothing very distinctive comes out of it, the TLF view elucidates an area of our moral thought about human lives in a way that is $\vec{\vartheta}$ significant in other contexts.

1) Leavitt says that our discussions of embryoso should inform actual moral decisions facing individ-s uals in concrete contexts, for instance women con-0 templating abortions, IVF workers deciding what to do with excess embryos, and those who can create embryos. He claims that the concept of TLF doeso not help with these decisions. Leavitt does not give ${ }^{3}$ us any other metaphysical view that meets his criterion of relevance although he does concede that both metaphysical views and religious views may dôs so. However, before we go looking for the relevant $\bar{D}$ views, we need some idea of what we are looking for.

There are particular metaphysical facts thas directly influence moral decisions. For instance consider an incommunicative human being who is deformed in ways of reminiscent of those in vegeta $\frac{D}{0}$ tive states. If this individual actually had experiences. that mattered to him - by causing him to feel, for instance, distress, joy, regret, anger and so on - then it would be almost impossible to neglect the implicit moral claims he made on us. Therefore this particu $-\frac{\omega}{\sigma}$ lar metaphysical belief - about his mind and its contents - influences our actions. However, hi⿺ moral properties and our metaphysical beliefs? about him are probably not connected by explicit syllogisms of the following type.

a) A person is entitled to life and liberty.

b) This is a person because he has properties $F, G \frac{0}{0}$ $\mathrm{H}$, and so on.

c) $\mathrm{He}$ is entitled to life and liberty.

There may be no premises like these prominent i⿳亠े⿵冂. our reasoning and therefore we may not be able t $\overrightarrow{+}$ 
examine the rational defensibility of such claims in trying to unpack our moral thinking.

It is more plausible that his existence engages with a diverse but inter-connected raft of ideas such as those giving rise to Strawson's 'reactive attitudes' (4). Strawson argues that our beliefs in such things as the freedom of the individual and her responsibility for her own actions are inseparable from reactive (including moral) attitudes such as resentment, indignation, praise, and so on. He argues that these attitudes are part of a conceptual scheme which is an integral part of our everyday life as human beings in relation to one another. This scheme is quite distinct from a view according to which human beings are objects caused by impersonal forces to behave in this or that way on the basis of internal mechanisms. What is more, Strawson argues that the reactive attitudes scheme - including concepts like freedom and resentment - is not only permissible in that it informs our normal dealings with other human beings, but is also rational because it is indispensable to those dealings. By contrast, the objective scheme in which mechanisms and impersonal forces are regarded as the origin of all events would, if uncritically applied to human behaviour, undermine the interpersonal attributes that structure our moral universe. For Strawson, it is not rational for us to allow any theory to overturn ways of acting and relating that are intrinsic to our nature as rational social beings.

When we look for similar patterns of thought in relation to embryos, we find that they are necessarily ambiguous. Some want to regard them straightforwardly as human beings and others recognise that embryos are not the kind of beings-in-relation about whom we are used to making moral judgements. What is more, the 'reactive scheme' view is problematic for a consequentialist interpretation of potentiality.

If our attitudes to things rest on the consequences of a certain course of events going in a particular way, we are left with exactly the problems that Leavitt details. By treating each human embryo as no more than the focus of a set of events that might result in a human being if not interfered with by ourselves or other influences, we lose a number of conceptual connections which relate what we think of that thing (or things of that type) to what we think of other things which have a certain place in our universe of discourse. In particular the 'object-pluspossible-futures' view loses some of the links with our moral attitudes that fuel our ethical reasoning.

We suggested that an embryo is a human being and that, according to the TLF view, our thoughts about human beings have shifting moral content depending on what part of the TLF is in question. A dying elderly man, for instance, is located in a network of relationships and social events which neither begin with his birth nor stop with his death and which draw on the totality of his life as a unique example of the human form. Therefore our attitudes (and moral judgements) do not rest merely on the fact that he is now a particular physical specimen with a range of possible futures depending on events. They relate to the totality of his life which includes what he would have wanted, how he copes with situations, the ways in which his words reflect his feelings and so on. This broader context allows us properly to evaluate the decisions that have to be made at any given point in an individual's life. Our aim was to orient our ethical thought toward this general context view as a way of approaching moral attitudes to human beings and the case of embryos aptly illustrates the results.

The aim of broadening our view in medical ethics brings us to the relationship, both in our metaphysical and moral thought, between particular and general features of situations.

2) We have sought to locate our moral attitudes to a general type of thing - a human embryo - in a wider range of considerations, concerning human life and inter-relatedness, growth and decline, joy and pain, and life and death, to name but a few. But Leavitt constantly dislocates moral judgement from this general context within which reasoning and justification are fashioned and tries to narrow our focus to a particular case and to a particularly superficial or narrow analysis of that case. He asks whether the view that a particular embryo is a human being at a certain point in the development of the TLF of humanity, differs at all from the view that it is a potential person (precise view of potentiality undefined). This misses our point about the general context of moral judgement and its relation to the perspective that ought to be taken on a particular problem. For instance, he asks what our view implies about the aborted embryo/fetus? We claim that there is some value, of the type associated with the life of a human being, to be taken into account in such a case. That is because the thing concerned is located in our thought as being of the type human being. This means that, even if a particular abortion is morally defensible, it is so because there are reasons of a type which prevail against the relevant degree of that kind of value. Our analysis links our moral thought to some very general features of human concept use. In our general thoughts about the world, we do not judge each item we encounter as an individual type (to do so would, in fact, make thought impossible (5)); we conceptualise any given thing as an instance of this or that general type in order to give it a cognitive form and reason about it. Thus we do not, contra Leavitt, judge this thing as an embryo that will be destroyed and therefore not of a type to be morally valued but rather as a human embryo whose fate is in our hands. That the two characterisations yield the same conclusion for practical reasoning in some particular case does not mean that they are morally or cognitively equivalent. If, for instance, the mother of the embryo is left with a load of guilt or an IVF 
worker is changed in her view of human life and death, these are moral outcomes even though they might not alter the particular practical conclusion in the case under discussion. Surely our aim in ethics should be to try and get a grip on those general understandings which reveal the connections in our moral universe rather than just delivering good enough solutions in a given case.

3) When we attempt to explain and locate our moral views in our general conception of life, the universe, and everything (which is a good description of metaphysics) we do more than quibble over ethically idle points of dispute. To try and reflect upon our moral intuitions in the light of broader beliefs is to prepare the way for genuine moral insights and to help to integrate our cognitive lives. If, for instance, one comes to the conclusion that there are no marks of the human soul that are not equally instanced by both black and white human beings, that metaphysical belief has profound implications for moral judgements. If, in the present context, we decide that a significant aspect of our attitudes to embryos is that we locate them in our metaphysics as human beings then that also is important. It is important because it invests them with a negotiable range of the moral as well as natural attributes proper to things of that type. This enables us to see aspects of the moral decision-making in pregnancy which we might otherwise neglect. That seems to be quite a significant thing to 'come out of' a metaphysical view even if it does not swing the pendulum against other factors in a given case or range of cases.

4) At this stage it remains to review the way I have tried to make good the TLF view's claim to relevance. It is relevant in the general sense that a metaphysical underpinning which explains and discloses the subtleties of our moral thought about a class of items is an important part of ethical analysis. It is also relevant because it helps us appreciate the weights that are involved in decisions about pregnancy and its continuation. Thirdly, it is relevant to the social concern about IVF and related techniques because it unpacks and allows us to reflect upon beliefs which make us uncertain in ways that we would not be were each embryo just a piece of tissue with a yet-to-be-decided future.

The TLF view argues that a thing begins when it first becomes an identifiable and re-identifiable particular of a given type and not before. It is clear that an embryo is an identifiable and re-identifiable object and that sperms and ova are merely parts of a process that may or may not produce such an object. This means that an intervention to end pregnancy would be expected to have different moral dimen- $\frac{\text { T. }}{\overrightarrow{\frac{T}{6}}}$. sions from one to prevent it. But that conclusion is, of course, quite compatible with the idea that the $\overrightarrow{\vec{s}}$ social and interpersonal values informing the one decision might also inform the other. In that sense the TLF view argues for a distinction between $\bar{m}$ contraception and abortion in a way that the conse- $\bar{\nabla}$ quentialist view does not but it does not entail that $\propto$ one is always morally permissible and the otheres always vicious.

We ought, in conclusion, to point out that we iden- $\vec{\omega}$ tified the TLF view as a kind of potentiality view and therefore it is slightly misleading for Leavitt to con- $₫$ trast us with the so called 'standard potentiality 0 view'. We are, however, definitely objecting to the consequentialist version of potentiality. We have argued for a metaphysical characterisation of theo embryo as the basis of a range of connected social and moral attitudes. We believe that this character- 3 isation makes sense of those attitudes in a way that $\frac{0}{7}$

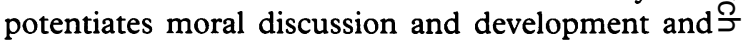
that therefore our case is not 'merely metaphysical' $\overrightarrow{0}$ in Leavitt's sense. If one believes, as I do, that ethics is wholly integral to, and therefore inseparable from our understanding of the world and our own place in it, then the view of forms we have defended in relation to the human embryo meets an extremely profound and far-reaching 'Criterion of Relevance'.

Grant Gillett is Associate Professor in Biomedical Ethics $\overrightarrow{\overrightarrow{\mathrm{O}}}$ at the Bioethics Centre, University of Otago Medical School, Dunedin, New Zealand.

\section{References and Notes}

(1) Leavitt F J. Let's keep metaphysics out of medical ethics: a critique of Gillett and Poplawski. Fournal of medical ethics 1992; 18: 206-209.

(2) Poplawski N, Gillett G. Ethics and embryos. Fournal of medical ethics. 1991; 17: 62-69.

(3) See reference (1): 208.

(4) Strawson P F. Freedom and resentment. In aㅡ. collection of the author's own essays, Freedom and $\mathrm{N}$ resentment and other attitudes. London: Methuen, 1974.

(5) It would make thought impossible because every $N$ thought is composed of concepts which capture gen-N eral features of things and link particular instances in $\sigma$ virtue of the fact that they are instances of this or that type. Thus when I judge that this object is square, red, incensed, or ugly I do so by forging conceptual con- $\mathbb{\complement}$ nections. I connect what is before me to the kinds of ${ }^{+}$ things we designate as objects, and then I make further connections to objects which instance the concept $\frac{+}{\circ}$ $<$ square $>,<$ red $>$... . I have discussed this at length in Gillett G. Representation, meaning and thought. $\overrightarrow{\mathbb{P}}$ Oxford: University Press, 1992 (esp ch1). 